\title{
Hacia una Historia Atlántica: visiones religiosas compartidas/
}

\author{
Perspectives on Atlantic History: \\ some shared views of religion
}

\author{
Jaime Contreras \\ y Rosa María Martínez de Codes \\ Universidad de Alcalá \\ y Universidad Complutense de Madrid
}

La historiografía de la cultura religiosa de los espacios atlánticos ha prestado escasa atención a los substratos comunes que la conformaron en el Nuevo Mundo. Lejos de reiterar los numerosos elementos que han diferenciado las formas culturales de colonización entre el espacio anglosajón y los espacios hispanos, se insiste en este estudio en el hecho de que fueron muchas las complementaciones entre ambos escenarios y que, en consecuencia, es preciso incidir más en esta línea de investigación. Ello ha de contribuir a asentar los elementos de una Historia Atlántica más integrada.

Palabras Clave: Historia Cultural; Religión; Historia Atlántica; Puritanismo; Catolicismo; Historia comparada.

Atlantic History has paid little attention to the common basis that originated a religious culture in the New World. This research rather than emphasizing the different cultural ways of colonizing in the British Empire and the Spanish Empire focuses on the complimentary aspects on both spaces in order to settle down those elements that contribute to a well-integrated Atlantic History.

KeYwords: Cultural History; Religion; Atlantic History; Puritanism: Catholicism; Comparative History. 
El siguiente trabajo no es, desde luego, un estudio acabado de historia comparada; no podía serlo en cualquier caso. Se trata, principalmente, de esbozar en él un conjunto de reflexiones que los autores estiman necesarias a modo de contribución para una historiografía, la de los espacios atlánticos, que todavía se debate en dudas e indefiniciones, tanto en el análisis de sus objetos, como en la precisión de sus métodos. Los autores de las consideraciones que aquí se expresan saben de las dificultades y de los riesgos que supone atreverse a hacer preguntas respecto de la naturaleza de la política moral en el devenir histórico de los dos espacios culturales de América. Mucho más cuando tales interrogaciones, formuladas en el mismo tono y en el mismo lenguaje, buscan encontrar respuestas a uno y a otro lado que, por supuesto, han de ser contrastadas.

"Visiones religiosas compartidas", decimos en el enunciado del trabajo y, desde luego, lo que con tal título se sugiere es comprender algunas de las múltiples facetas que las relaciones de ortodoxia y moral establecen entre sí, tanto en el marco de las colonias anglosajonas como en el espacio de los Reinos de Indias. Porque nos parece necesario, y hay muchas razones para ello, que la reflexión del historiador intente captar las múltiples formas de expresión de elementos culturales comunes en ambos lados, elementos que subyacen en los cimientos constitutivos de ambos conjuntos: el sedimento religioso inicial.

La historia de la cultura religiosa en Occidente, o más particularmente la naturaleza de esa historia expresada en los espacios atlánticos, ha venido manifestándose de forma dual en torno a dos paradigmas: por un lado, la cultura generada a través de las sucesivas reformas protestantes, que se ubica en el espacio anglosajón y, por el otro, la cultura que se expresa desde el espacio católico y cuyo territorio se circunscribe al mundo iberoamericano.

Estas culturas religiosas evolucionaron paralelamente desde sus propias estructuras internas y se definieron a sí mismas como universos autosuficientes y objetivados. Durante mucho tiempo ambos mundos apenas se reconocieron entre si y cuando lo hicieron se definieron mutuamente como el espacio del otro. Esto suponía que la percepción de ese otro distinto y diferente conllevaba el conocimiento reforzado de sí mismo.

Ambas culturas, aparentemente tan diferenciadas, y que se entendían ellas mismas como sistemas globales de significados, símbolos y creencias, tienen una historia centenaria. Tal historia nace, como es sabido, a finales del siglo XV, cuando por toda Europa se tenía la percepción de vivir tiem- 
pos nuevos, con motivo de la eclosión renacentista. Nacieron las dos culturas, pues, en una misma época, de un mismo tronco y por las mismas causas. Surgieron ambas de la gran crisis tardo medieval de la Universitas Cristiana.

Dicha Universitas era un enorme espacio global y civilizador que no pudo resistir los efectos disgregadores de tres fuerzas principales que, entonces, emanaron de su interior. Dichas fuerzas fueron las siguientes:

1. La firmeza enorme que demostraron tener, en aquel tiempo, las corrientes conciliaristas, las cuales conllevaban el correlato de Iglesias particulares.

2. El establecimiento jurisdiccional y político de las Monarquías, que además se reforzaban a través del control ejercido sobre sus Iglesias respectivas (lo que condujo al ejercicio del Patronato Regio, en el caso de las Monarquías católicas, o definieron a la Corona como cabeza de la Iglesia, en el caso de las Monarquías protestantes).

3. Como tercera fuerza puede indicarse la quiebra del principio eclesial de autoridad de fe, que se produjo tras el grito de Lutero en Worms, en 1520; grito que centró en la fuerza de la palabra de Dios, inseminada en el cristiano, el principio de la ortodoxia.

De estas tres fuerzas principales surgieron los dos grandes sistemas culturales que dominaron los espacios atlánticos desde el siglo XVI hasta el tiempo presente. Resulta difícil percibir, por razón de su tronco común, diferencias estructurales de peso. Los posteriores avatares históricos de ambos sistemas no fueron suficientemente determinantes, a su vez, para cambiar la naturaleza de los fundamentos iniciales y comunes.

Partiendo de esta tesis es posible interpretar que todas o la mayor parte de las divergencias entre ambos mundos que pueden, sin duda, detectarse, proceden, principalmente, de una percepción excluyente del otro; o bien de la creencia de la superioridad de los valores que católicos y protestantes siguen trasladando al pasado desde el espacio presente.

Se entiende que ambos sistemas culturales ahondaron las diferencias e intentaron hacerlas estructurales hasta el punto de verse de manera irreconciliable entre sí. Y de este modo dos historiografías centenarias se han ido construyendo sin reconocerse mutuamente, es decir de forma negativa; hasta el punto de presentar dos modelos de colonización - la hispana y la inglesa - de manera confrontada y, en el caso de Iberoamérica, también 
dependiente. Pocos han sido los historiadores que se han atrevido a romper esa tendencia.

Debe reconocerse que hoy, como menciona John Elliott, ${ }^{1}$ ninguna historiografía nacional puede justificarse en sí misma. No existe en la actualidad ningún sector historiográfico con posibilidades de desarrollo que reduzca sus metodologías ni sus hipótesis al interior de sus espacios naturales. Hoy domina por lo tanto un revisionismo historiográfico que formula preguntas cuyas respuestas sólo son posibles desde la comprensión de los dos sistemas mencionados, porque éstos presentan evoluciones y estructuras que el estudio comparado permite definir.

El papel que la religión jugó en ambos sistemas colonizadores ha sido interpretado mayoritariamente como una de las claves diferenciadoras de ambos procesos. No cabe duda que el establecimiento en el mundo anglosajón de diferentes iglesias, unas procedentes de otras por un proceso de múltiples subdivisiones, respondió sin duda alguna a la gran eclosión de grupos y sectas religiosas que tuvo lugar en Inglaterra durante los tiempos de la Revolución Gloriosa. En esa época la Iglesia de Inglaterra, Iglesia del establishment social y político, padeció los efectos reformistas ocasionados por la multiplicación de programas religiosos de naturaleza revolucionaria.

Por el contrario, en las colonias hispanas, la Iglesia Católica fue un instrumento de la Monarquía a efectos de la ocupación del territorio y de la evangelización de la población aborigen. En aquel tiempo, la Iglesia diocesana, cada vez más insertada en la estructura social del criollismo, asumió un programa doctrinal codificado y burocrático que terminó expulsando a la periferia del sistema los proyectos evangelizadores que algunas órdenes religiosas, entre ellas la Compañía de Jesús, intentaban desarrollar. Pero, en cualquier caso, en las Indias hispanas la transmisión de la fe resultó ser una exigencia ineludible del cristianismo; los teólogos y misioneros españoles se esforzaron por encontrar las fórmulas más adecuadas para garantizar la eficacia de la labor evangelizadora que la Corona tenía el deber de promover.

Más allá de estas diferencias, en el traslado de las culturas religiosas protestante y católica al Nuevo Mundo se pueden señalar convergencias notables. Desde el origen, estos dos sistemas culturales se construyeron por los impulsos de una entidad política dominante que, además, se encontra-

1 John Elliott: Do the Americas have a Common History? ¿Tienen las Américas una Historia Común? An Address, Providence, Rhode Island, The John Carter Brown Library, 1998. 
ba en proceso de desarrollo creciente. Esta entidad fue la Monarquía, estructura y cuerpo político pleno de soberanía y de jurisdicción. Institución que, sin ahogar las entidades políticas de representación (Cortes, Parlamentos y Asambleas), se reservó siempre para sí el principio de la plenitudo potestatis. La Corona, en ambas culturas, fue el principio del derecho positivo. Evolución paralela que se siguió en la Monarquía Católica de los Habsburgos hispanos, así como en la Inglaterra de los Tudor y los Estuardo. Y bajo ambas Coronas los cuerpos políticos con jurisdicción se ordenaron jerárquicamente.

Interesa destacar también que, en ambos sistemas, la Monarquía, además, generó una cultura confesional; es decir, fue definiéndose un régimen de "constitucionalismo estamental" (rey y reino) que entendió la uniformidad religiosa como la primera "razón de estado" y como el primero y más importante de los derechos de la ley divina que la comunidad política había de preservar. Deseamos recordar en este punto el discurso del principal ministro de Carlos I, William Laud, en 1625, en Whitehall, donde afirmaba que las diferencias de la fe eran: "The great and multiplied sin would lead a nation to inwardly melt". ${ }^{2}$

Sin embargo, la Corona de los Estuardo no pudo imponer la uniformidad religiosa en sus colonias. Los tiempos turbulentos de la Revolución de 1640 impusieron en el escenario social y en el espacio político la presencia del radicalismo religioso y doctrinal, un radicalismo, tan milenarista como anárquico, que generó el nacimiento de múltiples grupos de entidad mesiánica, algunos de los cuales emigraron a las colonias. En el ánimo de muchos de éstos estaba la idea de crear, en espacios remotos, el sueño de una iglesia evangélica y pura que, en la feliz metáfora de John Winthrop, sería la moderna Sión, una ciudad levantada sobre la colina: "We shall be as a Citty upon Hill, the eies of all people are uppon us". ${ }^{3}$

Pero más allá del desarrollo exitoso en lo social y en lo político, que algunos de estos grupos tuvieron, el verdadero interés de la Corona de Inglaterra respecto de sus colonias se centró en el modelo implantado en Virginia, cuando aquella "plantación" pasó bajo su control directo en 1624. Desde entonces en Virginia se reprodujo, como ocurrió de manera similar en el caso español, la misma estructura socio-cultural que el anglicanismo

2 The works of the most reverend father in God, William Laud, D.D., 7 vols, Oxford, J. H. Parker, 1847, p. 96.

3 Edmund Morgan S.: The Puritan Dilemma: the story of John Winthrop, Boston, Little, Brown and Company, 1958, p. 14. 
había desarrollado en el Reino Unido. Y así ocurrió que en las colonias hispanas el criollismo todavía vinculado a las estructuras institucionales de la Corona impuso el prototipo social del noble hidalgo y caballero. Del mismo modo en la sociedad virginiana se definió el prototipo de English Gentleman.

En el ámbito de las estructuras laborales y productivas puede establecerse, igualmente, cierto paralelismo. La encomienda hispana como sistema de trabajo dio paso a una forma más productiva tipificada en la hacienda; unidad de producción que, bajo el gobierno de la Compañía de Jesús, adoptó formulas de marcado carácter paternalista. En Virginia, en este tiempo, la gentry esclavista entendió la plantación de esclavos como una forma de producción definida como "his state in himself”. Así lo manifestaron las palabras de John S. Basset, un planter de finales del siglo XVII, cuando recordaba que: "(...) he wanted to group his slaves around him where he would know them, physic them, give them in marriage, and in his good-natured way train and swear at each one individually". ${ }^{4}$

Hombres como Basset, con esta cultura de cercanía al trabajo productivo, formaron la estructura social y política más sólida de Virginia. Ellos constituyeron y controlaron los centros neurálgicos de la vida social, política y judicial del mundo virginiano. La House of Burgeses, el Count Council o el Governor's Council fueron instituciones que precisaron todos los detalles de la vida y de la cultura de la colonia, desde la determinación del precio del tabaco hasta la precisión de cuáles debían de ser los modelos educativos y religiosos. Algo semejante al control burocrático que, en el espacio hispano, ejercieron las elites civiles y eclesiásticas asentadas en Cabildos, Audiencias y Diócesis.

Virginia, como la América española, fue gobernada, desde la confesionalidad anglicana, por gentes de propiedad y de derecho - the men of substance-, hombres que entendieron que la sociedad colonial no podía ser otra cosa sino la versión mejorada de la sociedad inglesa. Por ello los anglicanos de Virginia, los más legitimados de todos los colonos por su cercanía al gobierno, comprendieron que su colonia no debía asentarse sobre principios tan inestables como los que representaban los puritanos de Massachussets o los cuáqueros de Pennsylvania. Para los felices virginianos de los siglos XVII y XVIII, la cultura religiosa no podía ser ni utópica ni mesiánica sino, esencialmente, tradición.

4 Daniel J. Boorstin: The Americans: the colonial experience, New York, Random House, 1958, p. 103. 
Y fue esta tradición la que mantuvo la estabilidad de la sociedad virginiana. Su iglesia no pretendió construir, en aquel nuevo espacio, la ciudad de Sión, el sueño de los utópicos, sino extender por todo el conjunto social un silencioso y penetrante sentimiento (quietly pervasive sentiment), en el que las leyes de Dios se expresaban sin drama en la vida de los hombres. Esta gentry esclavista hablaba de una cultura religiosa con plena tradición, con la memoria y la legitimidad de los tiempos, al modo y forma como, por entonces, lo manifestaba la Iglesia católica. Se puede afirmar que la iglesia de Virginia despedía un aroma pleno de catolicidad.

Desde entonces hasta los inicios de la Revolución americana en los años 1770 el anglicanismo fue el único credo oficial de la colonia. Confesionalidad, pues, del gobierno de Virginia que implicaba, al igual que en el ámbito colonial católico, el sostenimiento de la Iglesia y sus ministros y el sometimiento a sus normas; así como la aceptación de un código moral y punitivo de conductas desviadas o disidentes: "That there be an uniformity in our church as near as may be to the canons in England; both in substance and circusntances, and that all persons yield ready obedience unto them under pain the censure...". 5

Cuando el Parlamento inglés aprobó la Ley de Tolerancia en 1689, en la estela de la Revolución Gloriosa, mantuvo los privilegios de la Iglesia Anglicana como religión oficial del Estado, aunque eximió a los creyentes de otras iglesias de las leyes que castigaban la disidencia.

En cualquier caso, la confesionalidad de la Monarquía se mantuvo pese al desarrollo de otras iglesias no anglicanas, con las cuales la Iglesia oficial mantuvo serios conflictos. Y así, en vísperas de la Guerra de Independencia, cinco colonias mantenían el anglicanismo como religión oficial: Maryland, Virginia, Carolina del Norte, Carolina del Sur y Georgia.

Está claro que en este caso se trata de una confesionalidad explícita y directa por razón de que el titular de la Corona era la cabeza primera de su propia Iglesia. En el caso español era la catolicidad la que expresaba la confesionalidad de la Monarquía, por cuanto, en razón de las doctrinas del derecho medieval, se otorgaba a la Santa Sede la iniciativa de la jurisdicción soberana de los príncipes cristianos. Una soberanía que se entendía en función del sustrato doctrinal que Roma definía.

5 William W. Hening (ed.): "Acts of the Virginia Colonial Government on Religion, 1624" en: The Statutes at large: being a collection of all the laws of Virginia, Volume 1, Richmond, Printed by and for Samuel Pleasants, junior printer to the Commonwealth, 1819, p. 149. 
La teoría teocrática, defensora de la potestad absoluta del papa como vicario de Dios en lo espiritual y en lo temporal, fue aceptada oficialmente por la doctrina áulica española como la base de un justo título de dominio de la Corona de Castilla sobre las Indias. Nos referimos a la concesión que otorgó Alejandro VI de los territorios descubiertos y por descubrir, después del primer viaje de Colón, a los reyes de Castilla y sus herederos. ${ }^{6}$

Más allá de los atributos convenidos o delegados a ambas Coronas, sus iglesias - la Iglesia Católica institucionalizada en Indias, la Iglesia de Inglaterra o las Iglesias Congregacionales de la Massachussets Bayentendieron y creyeron que su estructura político eclesial era una representación del Reino de Dios en la tierra, según la antigua tradición neoplatónica que expresó San Agustín. Resulta comprensible que ese concepto de Reino de Dios, para ser operativo, requiriese de unos códigos doctrinales y morales que los representantes de las Iglesias oficiales, al amparo de sus Coronas, imponían a sus creyentes y que los disidentes no acataban. De hecho, éstos también tenían su concepto unitario y objetivo del Reino de Dios, pero cuando reclamaban tolerancia y benevolencia para sus comunidades religiosas, se olvidaban de aplicar tales fórmulas a sus adversarios al alcanzar posiciones de dominio en otros territorios.

La historia de los espacios atlánticos está llena de ejemplos en tal sentido. Ello es consustancial con la doctrina de la propia Reforma protestante. Lutero reclamó al emperador que respetase su conciencia en la Dieta de Worms (1520), pero a continuación no tuvo escrúpulo para exigir la intervención militar de la nobleza alemana y así eliminar a los anabaptistas; Voltaire, un deista de tradición católica, en su Essai sur les moeurs et le esprit des nations, hizo una crítica despiadada de la figura de Calvino, al decir de él que pedía tolerancia en Francia, de la que tenía necesidad, pero se armaba de intolerancia en Ginebra, como demostró con el español Miguel Servet.

Ejemplos parecidos pueden detectarse en las colonias británicas en las que, bajo distintas formas de exclusión, la diversidad de credos, reclamada por los grupos disidentes, fue frecuentemente obstaculizada por las iglesias establecidas. Sirva de ejemplo la determinación con que las iglesias congregacionales de Massachusetts, en defensa de la ortodoxia puritana,

6 Juan Manzano y Manzano: La incorporación de las Indias a la Corona de Castilla, Madrid, Ediciones Cultura Hispánica, 1948. Alfonso García Gallo: Estudios de Historia del Derecho Indiano, Madrid, Real Academia de Jurisprudencia y Legislación, 1972; del mismo autor, Los orígenes españoles de las instituciones americanas, Madrid, Real Academia de Jurisprudencia y Legislación, 1987. 
procedieron a la expulsión de los líderes disidentes de otras comunidades - Roger Williams, Anne M. Hutchinson y Samuel Gorton- y prohibieron el establecimiento de colonos cuya ortodoxia no fuera contrastada por sus magistrados. ${ }^{7}$

Sorprende pues esta determinación tan rigurosa por la verdad, en iglesias que, durante el periodo turbulento de la Revolución, habían luchado por la libertad de conciencia desde la literatura de panfletos. Porque ocurrió que en Inglaterra, en aquellos difíciles años, diversas iglesias habían exigido que la verdad de fe se expresara en el espacio de la libertad. Ocurría ahora, por el contrario, que en Nueva Inglaterra estos mismos grupos defendían una teología bíblica para la cual la Iglesia de los Santos, es decir su iglesia, era la verdadera. En esta iglesia la verdad no se acompañaba de la libertad, no era una verdad sociológica, sino que era dogma. John Cotton, uno de los predicadores puritanos de mayor prestigio en la Bahía de Massachussets, entendía, citando a San Pablo, que el error fomentaba la división de la comunidad y que el hombre que se recreaba en ese error era enemigo de la misma, porque no sólo pervertía su propia conciencia, sino también la conciencia del grupo. Y así manifestaba que: "So that if such a Man after such Admonition shall still persist in the Errour of this way, and be therefore punished, He is not persecuted for Cause of Conscience, but for sinning against his Owne Conscience". ${ }^{8}$

El universo cultural religioso de los puritanos, a ambos lados del Atlántico, no contemplaba la tolerancia ni como principio doctrinal, ni como principio de gobierno. Por ello, la explosión de nuevos grupos, denominados sectas -los Quakers, los Ranters, los Seekers, los Levellers y los Diggers- en la Inglaterra de los años 1640 y 1650, produjo en las colonias una reacción sin precedentes entre los defensores de la ortodoxia. ${ }^{9}$

El triunfo de esta ortodoxia reactiva y particular, frente a las manifestaciones del error protagonizado por Católicos, Arminianos, Anabaptistas, Familistas, Arrianos, Independientes, Baptistas y Milenaristas, fue motivo de un conjunto de tratados, que identificaban la herejía en estos grupos e ilustraban las dificultades que la libertad de conciencia y de culto tuvieron

7 Carla Gardina (ed.): Liberty of Conscience and the Growth of Religious Diversity in Early America, (1636-1786), Providence, Rhode Island, John Carter Brown Library, 1986.

8 John Cotton: The Bloudy tenet washed, and made white in the Bloud of the Lambe: being discussed and discharged of bloud-guiltinesse by just defence, Massachusetts, Kessinger Publishing, 2003.

9 Ephrain Pagitt: Heresiography: or a description of heretickes and sectaries sprang up in these letter times, London, Printed by W.W. for William Lee, 1647. 
en el mundo anglosajón. Sólo a partir de principios del siglo XVIII la libertad religiosa comenzó a asumirse dentro del orden político y social del Cristianismo Protestante, aunque se trató de una libertad lastrada por prejuicios legales y sociales contra católicos romanos, judíos y ateos.

Merece la pena, por consiguiente, revisar una corriente historiográfica, dominante en el espacio atlántico anglosajón, que explica la historia de la tolerancia a partir de los principios que inspiraron la revolución inglesa de mediados del siglo XVII, considerada como el semillero de las posteriores ideas tolerantes del siglo XVIII. Los radicales ingleses, que durante los años de la llamada "fecunda libertad" — los 1640 y 1650 — especulaban sobre el fin del mundo y la llegada del milenio, pasado el fervor revolucionario, no fueron capaces de organizar estructuras eclesiales adecuadas a los fines que propagaban.

Desde todas estas sectas se reclamó una tolerancia que la censura eclesiástica y las distintas formas de jurisdicción de la Iglesia anglicana no podían permitir. Y, en consecuencia, a medida que tales grupos disidentes fueron definiendo sus programas, se puso en evidencia su oposición a la ley, a los derechos políticos existentes y a las normas de carácter teológico de la Iglesia Anglicana. Todo ello derivó en un enfrentamiento entre sectas y grupos que condujo a su descrédito y a su derrota. Sirva de ejemplo cómo los ranters desorganizaron las comunidades de los diggers; los baptistas excomulgaron a los ranters y a los cuáqueros; y éstos últimos atacaron a los baptistas y a los ranters por anticristianos. ${ }^{10}$ De hecho, estas iglesias en las plantaciones de Nueva Inglaterra predicaban la exclusión. Francis Higginson, predicador de Salem, defendió en New Englands Plantation su convencimiento de que su iglesia era la única verdadera: “(...) is, that we have here the true Religion and Holy Ordinances of Almightie God taught amongst us... thus we doubt not but God will be with us, and if God be with us, who can be against us?". ${ }^{11}$

Tanto la ortodoxia puritana de Nueva Inglaterra, como el principio de uniformidad religiosa de la Iglesia Anglicana, impidieron, a lo largo de todo el siglo XVII, el desarrollo de una teoría de la tolerancia que desterrase la coerción en materia de fe. Es verdad que la doctrina más clásica del constitucionalismo norteamericano, cuando se interroga sobre el origen del derecho de libertad religiosa, tiende a retrotraer los orígenes de esa libertad

10 Christopher Hill: El mundo trastornado. El diario popular extremista en la Revolución inglesa del siglo XVII, Madrid, Siglo XXI, 1983, p. 366.

11 Daniel J. Boorstin, The Americans..., p. 5. 
religiosa a la Carta real inglesa concedida por Carlos II a Roger Williams, en $1663 .{ }^{12}$

En este punto conviene indicar que La Charter of Rhode Island and Plymouth Plantation fue la primera en garantizar libertad religiosa a cualquier individuo de la colonia, pero no se puede olvidar que tal derecho o privilegio no tuvo un carácter universal, ni se plasmó en posteriores textos legales en el mundo colonial inglés, en el cual los papistas o católicos romanos fueron tajantemente excluidos, como muestran las Leyes aprobadas en Nueva York o Massachussets. ${ }^{13}$

Esta profunda y confesional intolerancia se extendió por todo el continente, desde la Bahía de Massachusetts hasta las cordilleras andinas y las llanuras de la Pampa argentina. De tal intolerancia se pueden ofrecer muchos ejemplos que provienen del lado católico hispano. Sin embargo, desde el espacio anglosajón esta percepción ha sido casi siempre soslayada por la historiografía. Conviene recordar a este respecto las palabras críticas del profesor Marty E. Marty: "It is hard to convince latter-day Americans that most of their colonial foreparents came not assure religious freedom in general but only to seek it for themselves. Many of them were ready to set up little empires that united church and state at least as firmly as had in Europe". ${ }^{14}$

En las colonias hubo minorías religiosas que se creyeron capacitadas para constituirse por sí mismas en Reino de Dios. El primer paso necesario para conseguir tal objetivo era constituirse en iglesia; una iglesia de advocaciones constantes a los tiempos del cristianismo primitivo, mitificado plenamente. La constitución de dicha iglesia partía del acuerdo entre cristianos, según las circunstancias que un grupo de "Elders" determinaba: “(...) be done in such a manner as all Circumstances considered (...) so, as if there be no errour of man concerning their determination". ${ }^{15}$ Se trataba por lo tanto de Iglesias sin jerarquía, descargadas de la autoridad tradicional del obispo de Inglaterra y, en suma, eran iglesias sin tradición. Sin embargo, éstas se consideraban legítimas porque decían compartir una experiencia de conversión singular, la cual era entendida en el reducido

12 Benjamin P. Poore (ed.): The Federal and State Constitutions, colonial Charters, and Other Organic Laws of the United States, Volume 2, Washington, D C, R.A. Brock, 1890, pp. 1595-1603.

13 John J. Patrick: Constitutional Debates on Freedom of Religion: Documentary History, Connecticut, Greenwood Press, 1999, p. 6.

14 Carla Gardina (ed.), Liberty of Conscience..., p. 13.

15 Daniel J. Boorstin, The Americans..., pp. 17-18. 
espacio del grupo iniciático, como la base primera de todo acto político y, por lo mismo, de gobierno o Coventing.

En cualquier caso, en Nueva Inglaterra, durante una parte importante de su periodo colonial, se entendió que este grupo de Elders, tenían como obligación solemne la ineludible tarea de castigar la herejía y el cisma; tarea fundamentalmente política y exigencia primera del gobierno de "santos" elegidos.

Por su parte los legisladores de Nueva Inglaterra, de tradición anglicana, siempre defendieron la adhesión de estas iglesias al sistema normativo inglés y fueron conscientes de la necesidad de adaptar las instituciones del Viejo Mundo a las nuevas condiciones de sus colonias. Sin embargo ocurría que la experiencia compartida de los miembros de estas Iglesias se traducía en códigos de conducta muy estrictos, que el Consejo de éstas consideraba como el gobierno de Dios. Y tal gobierno generaba normas que no estaban en consonancia plena con las leyes civiles de Inglaterra. En tal sentido, algunos juristas, como Thomas Lechford, ${ }^{16}$ entendían que la comunidad de fe, es decir la Iglesia, no podía ni debía constituirse en órgano de justicia ni de administración. La ortodoxia puritana, por el contrario, permitía en este punto que las normas "civiles" castigasen, con la pena capital, delitos que en las leyes inglesas no merecían tal castigo: la idolatría, la blasfemia, el robo, el adulterio, el perjurio, la maldición de los hijos, etc. Formas delictivas todas ellas derivadas de las sentencias del Éxodo y del Deuteronomio, considerados por estas Iglesias de elegidos como sus ordenamientos penales fundamentales.

No hubo, por supuesto, tal enfoque bíblico en la percepción de la heterodoxia por parte del mundo hispano; está claro que no podía haberla porque en asuntos de fe, ésta venía definida por Roma. Tampoco el Tribunal del Santo Oficio incrementó las formas y maneras de castigo usuales en determinados delitos de heterodoxia, como la blasfemia, cuya jurisdicción compartía con las justicias ordinarias. Pero lo importante es entender que, en ambos hemisferios, se asumió, sin demasiadas trabas conceptuales, que el pecado, entendido como trasgresión de la Ley Divina, era también un delito, es decir, trasgresión, igualmente, de la Ley Positiva.

Las colonias atlánticas del mundo anglosajón no tuvieron que hacer frente, como las pertenecientes al mundo ibérico, al problema teológico y

16 Plain Dealing: or Newes from New-England, 1642, Providence, Rhode Island, The John Carter Brown Library. 
jurídico que supuso la posible apostasía de los llamados cristianos nuevos (convertidos desde el judaísmo o desde el Islam). Pero en algunos casos definieron también la herejía con parámetros parecidos a los utilizados en el espacio católico. Es verdad que frente a este delito no se dispuso en las colonias británicas de un dispositivo tan "político" como fue el de la Inquisición. No obstante conviene indicar, más allá de los tonos apologéticos de la Leyenda Negra, que el famoso Tribunal, más que castigar el error en la fe, se organizó tanto en el Viejo como en el Nuevo Mundo como una pieza más en el engranaje de la maquinaria político eclesial. ${ }^{17}$ Dicha maquinaria, operando bajo los criterios de la Monarquía, intentaba conseguir un cierto grado de disciplinamiento social y moral que era consecuencia de la aplicación de la ortodoxia.

En este punto el Tribunal del Santo Oficio no buscó tanto la represión de la heterodoxia, como lo prueba el análisis cronológico de su actividad procesal represora, sino que más bien intentaba que el cristiano adecuase su comportamiento público a los dictados de la doctrina y de la moral hegemónicas, con moderada precaución. De hecho, en todo el territorio de la Monarquía Hispana se desarrolló una precisa "pedagogía de la precaución". ${ }^{18} \mathrm{Y}$ debemos indicar que, en esta tarea, la acción de los inquisidores era complementaria de la que otras Instituciones desarrollaban, tales como las órdenes religiosas, las justicias civiles, y el clero secular. Unos y otros buscaron, más que la aplicación de penas y castigos, los efectos de la fraterna corrección y de las sanciones espirituales. ${ }^{19}$

En consecuencia no es extraño comprobar que, para el control de las disfunciones religiosas y morales, se expresaron fórmulas previas de negociación en función de motivos sociales e intereses de grupos. El ejercicio de las misiones de las órdenes religiosas pone de manifiesto algunas formas de mediación, como las que se emplearon en el Perú de principios del siglo XVII para controlar el culto idolátrico de las Huacas. ${ }^{20}$

Estas formas de corrección socio-moral, que no hablan de tolerancia sino de administración política de la disidencia, no parecen muy alejadas

17 Solange Alberro: Inquisición y Sociedad en México 1571-1700, México, Fondo de Cultura Económica, 1988, pp. 145-197.

18 Stuart B. Schwartz: All can be saved: Religious Tolerance and Salvation in the Iberian Atlantic World, London, Yale University Press, 2009.

19 Paolo Broggio: Evangelizzare il mondo, Roma, Carocci Editore, 2004.

20 Kenneth Mills: Idolatry and its enemies. Colonial Andean Religion and Extirpation, 16401750, Princeton, Princeton University Press, 1997. 
de las empleadas por la Iglesia de Inglaterra, incluso antes de la Guerra Civil. Es el caso de la Policy in piety, aconsejada como preferente por el mismo William Laud para controlar determinadas acciones contra la moral pública. En cualquier caso, los Tribunales que vigilaron la ortodoxia en Inglaterra, entendieron que la santa violencia debía ir precedida, igualmente, de una fraterna corrección.

Tales estrategias requerían, para ser eficaces, del empleo de formas interactivas de control de la disidencia. Los aparatos eclesiásticos en las Indias españolas tuvieron graves problemas para aplicar formas precisas y eficaces de control, dado el inmenso territorio que comprendían los Virreinatos, las Audiencias y las Gobernaciones y ello posibilitó que se aceptaran, de hecho, amplias formas de laxitud moral.

Por su parte, en el horizonte de Nueva Inglaterra la diversidad de comunidades religiosas y su proximidad, exigía, a priori, mecanismos de control más endogámicos. Las fórmulas que la pedagogía puritana desarrolló para expresar un correcto equilibrio entre el universo del castigo y el universo del perdón fueron expuestas, por los líderes religiosos de las distintas iglesias, en los miles de sermones que fueron impresos a lo largo de todo el periodo colonial.

En las formas de piedad puritana de Nueva Inglaterra y en el espacio religioso de los cuáqueros de Pennsylvania, por ejemplo, el control social ejercido a través del culto siempre estuvo focalizado en el púlpito y no en el altar. En estas Iglesias de base bíblica se oía la palabra de Dios y de ellas se seguía unas estrictas normas de conducta; es decir, una teología práctica y rigorista perfectamente adecuada al medio hostil en el que la comunidad vivía.

En el espacio público del sermón dominical, momento culminante de la religiosidad pública en estas iglesias de elegidos, se expresaba tanto la sociabilidad positiva como la sanción moral. Al pastor de las mismas le correspondía expresar los contenidos de la ortodoxia y los modos más acertados para poder soportar los peligros de la vida; para el conjunto de fieles el sermón servía para recordar sus naturalezas pecadoras y la condenación que de ello se seguía. Se trataba de un drama público en la Meeting House dominical, cuyo propósito era imponer una teología práctica de las conductas en una iglesia que construía una nueva Sión en tierras hostiles.

Esta teología práctica tuvo diferentes manifestaciones en las colonias de estricto dominio anglicano. En ellas, a semejanza del espacio hispano, la práctica religiosa se expresaba, no tanto en el sermón, cuanto en el con- 
trol de las instituciones. Instituciones eclesiales vinculadas a las parroquias y párrocos, en el caso de Virginia, más dependientes de los hombres de la House of Burgeses que del obispo de Londres. Eran de hecho instituciones parroquiales "secularizadas" que controlaban la moral pública, las expresiones de la caridad colectiva, la vigilancia de la educación... y las formas de relaciones sociales. Porque en Virginia la parroquia, así como en las Indias hispanas, fue el lugar, no tanto de la conversión del cristiano, sino el espacio social y moral donde se expresaba el arte de la política. Aquí las sanciones fueron escasas y no hubo lugar para milagros, como decían ver y sentir los congregacionalistas de la Bahía de Massachussets. Y tales fórmulas tuvieron su aplicación práctica en las leyes aprobadas por los sucesivos gobiernos de las colonias, donde además se penalizaban la no contribución pecuniaria a las cargas de las iglesias, independientemente de su condición civil o religiosa. ${ }^{21}$

No resulta difícil observar la existencia de equilibrios similares entre las fórmulas del castigo y del perdón en el mundo colonial español. En este sentido, la predicación misionera de las órdenes religiosas bien puede servir de ejemplo. Tales predicaciones consideraban que América era una esperanza para la Iglesia Católica a la vista del asedio a que ésta era sometida en Europa, "esta Iglesia ya ha llegado hasta la mar —explicaba el dominico Francisco Meneses en 1554- y aunque no ha pasado allende hasta agora, vemos que Dios en aquel desierto de las Indias (...) la edifica a gran priesa". ${ }^{22}$ Estas predicaciones que en el espacio hispano tuvieron una enorme extensión e intensidad buscaban tres objetivos principales:

En primer lugar se predicaba para conseguir la expiación social de los pecados públicos a través de un equilibrio entre la vergüenza pública y la fraterna corrección. Entre los principales pecados públicos figuraban la blasfemia, la idolatría y el amancebamiento.

En segundo término, y como objetivo principal de la predicación, se buscaba introducir la frecuencia del sacramento de la confesión a través de la conquista de la confianza y del afecto. Naturalmente ganar tal confianza suponía realizar campañas complejas de convencimiento público y privado. Sólo así se podía obtener la adhesión a unas formas de culto a tra-

21 Nathaniel B. Shurtleff (ed.): "Acts of the Massachusetts Colonial Government on Religion, 1638", en Records of the Governor and Company of the Massachusetts Bay, Vol. 1, Boston W. White, Printer to the Commonwealth, 1853, p. 240.

22 Felipe de Meneses: Luz del alma cristiana, Salamanca, Fundación Universitaria Española, 1978 , p. 368. 
vés de la actitud comprensiva del predicador. Ello suponía que se garantizaba el secreto de confesión y que se extendía lo más posible la absolución en el foro de conciencia, especialmente en el delito de idolatría. Tales estrategias las supo ofrecer la pastoral jesuítica con notorio éxito en el territorio del Perú: “(...) Los padres acudieron al remedio del alma del indio, con el cual tuvieron largos razonamientos y después de haberle predicado, se confesó dos veces y se arrepintió de su pecado, y pidiendo una disciplina se azotó, y muy alegre volvió diciendo que si fuesse menester haría más penitencia, y con esso y un rosario y estar algunos días aprendiendo al doctrina cristiana se fue muy consolado y contento ese indio ganado para su criador". ${ }^{23}$

Por último, esta predicación pretendía también que los frailes comprendieran que el objetivo de cristianización no podía olvidar la necesidad de intervenir, como mediadores, entre clanes y grupos locales. Estos religiosos, que actuaban como líderes en el conflicto, buscaban crear un clima de caridad colectiva, que podía expresarse en un acto público de reconciliación: “(...) Salió el Padre Rector y sacó a las cabezas de los bandos de la plaza y por aquella tarde se sosegó este fuego hasta que por la mañana y en otros tres días siguientes se concluyó el negocio, de suerte que una tarde trujo el Padre Rector a nuestra casa a todas las cabezas de los bandos (...) se abrazaron los unos a los otros y se estuvieron un gran rato en buena conversación y se acabaron los grandes daños que se tenía". ${ }^{24}$

En resumen, aunque tales objetivos fueron muy frecuentemente incumplidos en las Indias españolas, ello no es obstáculo para entender que fueron considerados como objetivos necesarios del plan divino para su Iglesia, Iglesia entendida como Reino de Dios para españoles y nativos.

Por su parte, aunque no todos los colonos ingleses entendieron la colonización como una revelación directa de Dios, fundamentalmente los asentados en las colonias de religión anglicana, es verdad que fueron bastantes los lideres religiosos puritanos que indicaron, con insistencia, la dimensión profética de su presencia en el continente: el Todopoderoso había proporcionado el Nuevo Mundo como un refugio para los rectos, un campo fértil para trabajar conforme a su divina voluntad y una tierra prometida para su pueblo elegido. La identificación de aquellos puritanos con

23 Littera Annua de la Provincia del Perú, 20 de abril de 1610, MPER, Monumenta Historica Societatis Jesu, VII, pp. 76-77.

24 Carta del provincial Rodrigo de Cabrero a Claudio Acquaviva, 30 de abril de 1601, Ibídem, p. 441 . 
el pueblo de Israel, salvado del dominio del faraón, era un recurso constante en la literatura de los sermones. Baste sólo un ejemplo. En 1630, el reverendo John Cotton, uno de los más relevantes clérigos de Nueva Inglaterra, recreó el mito de la tierra prometida al garantizar a los primeros emigrantes que salían hacia la Bahía de Massachusetts, en su sermón Gods promise to his Plantation, ${ }^{25}$ que ellos eran los elegidos para poblar el Nuevo Mundo, donde podrían establecer una comunidad santa que funcionaría como modelo de rectitud para el Viejo Mundo.

Parece evidente que Cotton entendía la Nueva Inglaterra como la Nueva Jerusalén de la Iglesia reformada. Iglesia que tras su caída inevitable traería el espacio del milenio, un tiempo de conversión de judíos y otros gentiles como etapa previa para el Juicio Final. Utopías milenaristas que, con notables diferencias cronológicas, se dieron en ambos espacios de colonización.

Pero quizá el principal problema a resolver resida en conocer cómo ambas culturas religiosas, anglosajona e hispana, consiguieron controlar la conciencia colectiva. Parece que los predicadores puritanos, en general, buscaron realizar una revolución cultural cuyo objetivo principal era luchar contra el hombre natural, es decir el hombre inclinado por naturaleza al pecado, como indicaba Henry Parker cuando en 1642 escribía: “(...) Al estar pervertido el hombre por la caída de Adán, éste se había convertido en una criatura tan indómita y tan incivil que la ley de Dios escrita en su pecho no bastaba para impedirle la maldad". ${ }^{26}$

Por su parte los clérigos de la Iglesia de Roma, al confesar, se erigían en intermediarios entre Dios y los hombres y, en cierto modo, los confesados, con la absolución y las penitencias espirituales, conseguían tener un cierto sistema de seguridad en la salvación. En la cultura protestante, sin embargo, el cara a cara con la Divinidad fue inevitable, porque con la Reforma se siguió conservando la tradición de la gravedad de la culpa y el sistema de seguridad, es decir, la confesión y la absolución desaparecieron. Liberarse de los clérigos no suponía en esta cultura liberarse de los terrores de la culpa.

En suma, el análisis de los desarrollos históricos de la cultura religiosa protestante y católica en las colonias británicas y españolas del Nuevo

25 John Cotton: God promises to his plantation, London, 1630. The John Carter Brown Library, Providence, Rhode Island.

26 Hill, El mundo trastornado..., p. 146. 
Mundo, requiere una metodología comparada que permita, no sólo cuestionar los paradigmas de nuestra historiografía tradicional, sino elaborar hipótesis que mejoren el conocimiento de ambos sistemas de significados, símbolos y creencias.

Recibido el 06 de noviembre de 2008

Aceptado el 21 de diciembre de 2009

\section{Bibliografía}

Solange Alberro: Inquisición y sociedad en México 1571-1800, México, Fondo de Cultura Económica, 1988.

Daniel J. Boorstin: The Americans: the colonial experience, New York, Random House, 1958.

Paolo Broggio: Evangelizzare il mondo, Roma, Carocci Editore, 2004.

John Cotton: The Bloudy tenet washed, and made white in the Bloud of the Lambe: being discussed and discharged of bloud-guiltinesse by just defence, Massachusetts, Kessinger Publishing, 2003.

- God promises to his plantation, London, 1630, The John Carter Brown Library, Providence, Rhode Island.

John Elliott: Do the Americas have a Common History? ¿Tienen las Américas una Historia Común? An Address, Providence, Rhode Island, The John Carter Brown Library, 1998.

Carla Gardina (ed.): Liberty of Conscience and the Growth of Religious Diversity in Early America, (1636-1786), Providence, Rhode Island, John Carter Brown Library, 1986.

Alfonso García Gallo: Estudios de Historia del Derecho Indiano, Madrid, Real Academia de Jurisprudencia y Legislación, 1972.

- Los orígenes españoles de las instituciones americanas, Madrid, Real Academia de Jurisprudencia y Legislación, 1987.

William W. Hening (ed.): "Acts of the Virginia Colonial Government on Religion, 1624" en: The Statutes at large: being a collection of all the laws of Virginia, Volume 1, Richmond, Printed by and for Samuel Pleasants, junior printer to the Commonwealth, 1819.

Christopher Hill: El mundo trastornado. El diario popular extremista en la Revolución inglesa del siglo XVII, Madrid, Siglo XXI, 1983.

William Laud: The works of the most reverend father in God, _, D.D., 7 vols., Oxford, J. H. Parker, 1847.

Juan Manzano y Manzano: La incorporación de las Indias a la Corona de Castilla, Madrid, Ediciones Cultura Hispánica, 1948. 
Felipe de Meneses: Luz del alma cristiana, Salamanca, Fundación Universitaria Española, 1978.

Kenneth Mills: Idolatry and Its Enemies. Colonial Andean Religion and Extirpation, 1640-1750, Princeton, Princeton University Press, 1997.

Edmund Morgan S.: The Puritan Dilemma: the story of John Winthrop, Boston, Little, Brown and Company, 1958.

Ephrain Pagitt: Heresiography: or a description of heretickes and sectaries sprang up in these letter times. London, Printed by W.W. for William Lee, 1647.

John J. Patrick: Constitutional Debates on Freedom of Religion: Documentary History, Connecticut, Greenwood Press, 1999

Plain Dealing: or Newes from New-England, 1642, Providence, Rhode Island, The John Carter Brown Library.

Benjamin P. Poore (ed.): The Federal and State Constitutions, colonial Charters, and Other Organic Laws of the United States, Volume 2, Washington, DC, R.A. Brock, 1890, pp. 1595-1603.

Stuart B. Schwartz: All can be saved: Religious Tolerance and Salvation in the Iberian Atlantic World, London, Yale University Press, 2009.

Nathaniel B. Shurtleff (ed.): "Acts of the Massachusetts Colonial Government on Religion, 1638", en Records of the Governor and Company of the Massachusetts Bay, Vol. 1, Boston W. White, Printer to the Commonwealth, 1853. 